\title{
PENGARUH KESADARAN WAJIB PAJAK DAN SANKSI PAJAK TERHADAP KEPATUHAN WAJIB PAJAK DALAM MEMBAYAR PBB DI KECAMATAN NGIMBANG KABUPATEN LAMONGAN TAHUN 2016
}

\author{
Zanuar Putra Ardwianto \\ Fakultas Ekonomi, Universitas Islam Lamongan \\ Abid Mutharom \\ Fakultas Ekonomi, Universitas Islam Lamongan \\ abid@unisla.ac.id \\ Haris Bashory Ismail \\ Fakultas Ekonomi, Universitas Islam Lamongan
}

\begin{abstract}
ABSTRAK
Latar belakang penelitian ini adalah memberikan ilustrasi tentang pengaruh kesadaran wajib pajak dan sanksi pajak terhadap kepatuhan wajib pajak untuk membayar pajak bumi dan bangunan. Teknik pengambilan sampel dalam penelitian ini adalah menggunakan Simple Random Sampling pada wajib pajak. Disebut sederhana karena mengambil anggota dari populasi secara acak tanpa mempertimbangkan tingkat populasi di populasi tersebut. Alat analisis data yang digunakan dalam penelitian ini adalah uji kualitas data, uji asumsi klasik, uji model dan uji hipotesis. Seiring dengan permasalahan dan hipotesis penelitian ini dilakukan dengan regresi berganda, sedangkan uji hipotesis menggunakan uji $t$ dan uji $f$ pada tingkat signifikan 5 persen dengan SPSS. Dari uji regresi berganda, didapatkan $Y=1,271+0,381 X_{1}+0,501 X_{2}$ + e. Dari uji t maka dapat dihitung variabel kesadaran wajib pajak (3.328), sedangkan sanksi pajak (4.284) variabel bebas memiliki nilai $t$ hitung lebih besar dari t tabel (1.984). Artinya variabel independen sebagian dipengaruhi variabel dependen. Dari hasil uji $F$ didapatkan $F$ hitung sebesar 79,620 lebih besar dari $F$ tabel 2,70. Jadi variabel independen berpengaruh secara simultan terhadap variabel dependen. Variabel paling dominan yang mempengaruhi kepatuhan wajib pajak adalah variabel sanksi pajak karena memiliki nilai Standard Coefficient Beta sebesar 0,465. Dari hasil penelitian dapat disimpulkan bahwa kesadaran wajib pajak dan sanksi pajak berpengaruh terhadap kepatuhan wajib pajak membayar pajak bumi dan bangunan di Ngimbang, Lamongan pada tahun 2016. Variabel yang paling dominan mempengaruhi kepatuhan wajib pajak adalah variabel sanksi pajak karena memiliki Standard Coefficient Beta sebesar 0,465.
\end{abstract}

Kata kunci: Kesadaran Wajib Pajak, Sanksi Pajak, Kepatuhan Wajib Pajak 


\section{PENDAHULUAN}

Pajak sangat berkaitan dengan kehidupan kita sehari-hari, semisal pajak penghasilan, pajak pertambahan nilai, pajak penjualan atas barang mewah, pajk kendaraan bermotor, dan juga pajak bumi bangunan. Segala sesuatu tentang pajak pun sudah di atur dalan UndangUndang, jadi kalaupun ada yang membangkan atau tidak mau membayar pajak pasti akan dikenakan saksi, pajak juga sangat penting untuk pembangunan infrastruktur semisal jalan, bendungan, irigasi dan banyak lainya, jadi tidak ada ruginya kita membayar pajak, semua pasti akan kembali pada kebaikan diri kita sendiri. Cukup kesadaran yang perlu ditanamkan kepada seluruh rakyat Indonesia agar patuh untuk membayar pajak. Untuk membantu peningkatan dalam penerimaan daerah, beberapa kebijakan yang akan ditempuh antara lain yaitu optimalisasi sumber pendapatan daerah serta meningkatkan kesadaran masyarakat dalam membayar pajak. Motivasi, penyuluhan serta pendidikan secara dini mengenai perpajakan telah diberikan kepada masyarakat untuk mendukung tumbuhnya tingkat kesadaran masyarakat serta didampingi pula oleh peningkatan pelayanan dan beberapa sanksi yang tegas.

Badan keuangan negara memiliki fungsi mengatur segala sesuatu tentang pembayaran pajak. Meski suatu bisnis merupakan kepemilikan pribadi, mereka harus mentaat iperaturan yang telah dibuat oleh negara. Badan keuangan tersebuat memiliki hak untuk mengawasi segala aktivitas bisnis mereka. Dalam jurnal (Iulia Caprian ,2015)

Pajak sebagai suatu kewajiban menyerahkan sebagian dari kekayaan ke kas Negara yang disebabkan suatu keadaan, kejadian, dan perbuatan yang memberikan kedudukan tertentu, tetapi bukan sebagai hukuman, menurut peraturan yang ditetapkan pemerintah serta dapat dipaksakan, tetapi tidak ada jasa timbale balik dari Negara secara langsung, untuk memelihara kesejahteraan secara umum. (Djajadiningrat dalam Sudirman, dkk 2016:2)

Pajak merupakan alat bagi pemerintah dalam mencapai tujuan untuk mendapatkan penerimaan baik yang bersifat langsung maupun tidak langsung dari masyarakat guna membiayai pengeluaran rutin serta pembangunan nasional dan ekonomi masyarakat. Sistem perpajakan selalu 
mengalami perubahan dari masa kemasa sesuai perkembangan masyarakat dan Negara, baik dalam bidang kenegaraan maupun dalam bidang sosial dan ekonomi.

Fungsi utilitas pembayar pajak ditentukan oleh beberapa variabel yaitu konsumsi, pekerja dan kecenderungan pengelapan pajak. Dalam jurnal (Pankiewicz ,2011) Jenis pajak yang diperhitungkan pada sisi penerimaan dalam APBN antara lain pajak penghasilan, pajak pertambahan nilai, bea masuk, cukai, ekspor, pajak bumi dan bangunan, pajak lainnya dan penerimaan bukan pajak. Khususnya untuk pajak bumi dan bangunan sebagian besar penerimaannya merupakan pendapatan daerah. Objek yang dikenakan pada pajak bumi dan bangunan ini adalah nilai jual objek pajak bumi dan bangunan.pungutan yang dilakukan oleh pemerintah dilakukan pembagian sebagaimana diatur oleh undang-undang yaitu bagi pemerintah kabupaten, provinsi, dan pemerintah pusat.

Wajib pajak sebagai tidak aktif adalah prosedur didirikan pada kondisi hukum secara tegas diatur dan memiliki kedua efek individu dan efek pada hubungan didirikan antara wajib pajak aktif dan satu aktif. Dalam jurnal (Despina Martha, 2013)

Pajak Bumi dan Bangunan merupakan salah satu jenis pajak yang penerimaannya dapat dioptimalkan dan cukup potensial untuk ditingkatkan mengingat objek dari Pajak Bumi dan Bangunan itu sendiri adalah meliputi seluruh Bumi dan Bangunan yang berada di Wilayah Negara Kesatuan Republik Indonesia. Pentingnya pajak sebagai sumber pembiayaan pembangunan telah ditetapkan dalam berbagai peraturan pemerintah dimana dalam Neraca Anggaran Pendapatan dan Belanja Negara telah ditentukan penerimaan Negara dalam pembangunan. Salah satu jenis pajak yang pemungutannya menjadi wewenang pemerintah daerah adalah Pajak Bumi dan Bangunan, dengan wajib pajak adalah Wajib Pajak Orang Pribadi dan Wajib Pajak Badan, dengan kewajiban pembayaran Pajak hanya 1 (satu) kali dalam setahun.

Penelitian ini di adakan karena peneliti tertarik untuk mengetahui bagaimanakah kesadaran masyarakat khususnya di Kecamatan Ngimbang akan membayar pajak bumi dan bangunan serta pengetahuan mereka akan adanya sanksi jika mereka tidak membayar pajak, Peneliti ingin 
mengetahui apakah masyarakat di desa yang mayoritas adalah seorang petani atau penambang sama dengan masyarakat yang di kota. Dikarenakan kawasan pedesaan merupakan kawasan yang jauh dari pusat pemerintahan tentunya kita menginginkan kesadaran masyarakat pedesaan akan membayar pajak bisa sama dengan kesadaran masyarakat yang ada di kota. Dalam hal ini juga peneliti tertarik untuk melakukan penelitian di Kecamatan Ngimbang ini dikarenakan pernah terjadi adanya fenomena kasus tentang wajib pajak yang lalai membayar sanksi denda pajak bumi dan bangungan pada desa munungrejo di Kecamatan Ngimbang pada tahun 2016.

\section{TINJAUAN PUSTAKA}

\subsection{Pengertian Pajak}

Menurut (Supramono, 2014:2) pajak merupakan iuran dari rakyat kepada negara berdasarkan UndangUndang (yang dapat dipaksakan) dengan tidak mendapat jasa timbale (kontraprestasi) yang langsung dapat ditunjukkan dan yang digunakan untuk membayar pengeluaran-pengeluaran umum.

\subsection{Pajak Bumi dan Bangunan}

Sudirman dkk (2016:391) mengatakan bahwa Pajak Bumi dan Bangunan adalah pajak yang dikenakan kepada seseorang atau badan hukum yang memiliki, menguasai, memperoleh manfaat bangunan dan/ atau mempunyai hak atau manfaat atas permukaan bumi.

\subsection{Kesadaran Wajib Pajak}

Kesadaran Wajib Pajak dalam membayar pajak merupakan perilaku Wajib Pajak berupa pandangan atau perasaan yang melibatkan pengetahuan, keyakinan dan penalaran disertai kecenderungan untuk bertindak sesuai stimulus yang yang diberikan oleh sistem dan ketentuan pajak tersebut. Mardiasmo (2011:41)

\subsection{Sanksi Pajak}

Mardiasmo (2011:59) mengatakan bahwa sanksi perpajakan merupakan jaminan bahwa ketentuan peraturan perundang-undangan perpajakan (norma perpajakan) akan dituruti / ditaati / dipatuhi. Atau bisa dengan kata lain sanksi perpajakan merupakan alat pencegah (preventif) agar wajib pajak tidak meleanggar norma perpajakan. 


\subsection{Kepatuhan Wajib Pajak}

Menurut kamus umum besar Bahasa Indonesia (1995:1013) istilah Kepatuhan adalah tunduk atau patuh pada ajaran atau aturan. Dan wajib pajak menurut Sudirman, dkk (2016:16) mengatakan bahwa wajib pajak adalah orang pribadi atau badan yang menurut ketentuan peraturan perundangundangan perpajakan ditentukan untuk melakukan kewajiban perpajakan, termasuk pemungut pajak atau pemotong pajak tertentu.

\section{METODOLOGI PENELITIAN}

\subsection{Jenis Penelitian}

Dalam hal ini Jenis penelitian yang digunakan dalam penelitian ini adalah jenis penelitian kuantitatif. Menurut Sugiono (2014:8), metode penelitian kuantitatif dapat diartikan sebagai metode yang berlandaskan pada filsafat positivisme, digunakan untuk meneliti pada populasi atau sampel tertentu, pengumpulan data menggunakan instrument penelitian, analisis data bersifat kuantitatif atau stastistika, dengan tujuan untuk menguji hipotesis yang telah ditetapkan.

\subsection{Jenis Data}

Sumber data dalam penelitian ini yaitu dengan penyebaran kuisioner yang diberikan kepada responden (Wajib Pajak) yang berada di wilayah penelitian secara acak dan proporsional.

Data yang digunakan dalam penelitian ini adalah jenis data primer dan data skunder sebagai data pendukungnya.

1) Data Primer

Data primer diperoleh dengan menggunakan metode survei, yaitu dengan menyebar kuisioner / pernyataan kepada responden sejumlah 100 responden dari desa yang berada di kecamatan Ngimbang. Untuk mengumpulkan informasi yang terkait kesadaran wajib pajak dalam membayar PBB. Kuisioner Kesadaran Wajib Pajak, Sanksi Pajak dan Wajib Pajak dalam membayar PBB.

2) Data Sekunder

Data sekunder sebagai data pendukung merupakan sumber data yang diperoleh secara tidak langsung melalui perantara (diperoleh dan dicatat oleh pihak lain). 


\subsection{Teknik Penarikan Sampel}

a. Populasi

Populasi dalam penelitian ini adalah wajib pajak PBB yang berada di kecamatan ngimbang. Jumlah populasi sekitar 47.255 dari 19 desa.Wajib pajak yang terdapat dalam buku PBB tahun 2016 untuk desa dalam wilayah kecamatan ngimbang.

b. Sampel

Karena karekteristik dari sampel yang sangat beragam, maka pengambilan sampel tidak bias sembarangan dan hanya menghitung dari prosentasi populasi. Teknik pengambilan sampel dalam penelitian ini yakni menggunakan metode sampel acak sederhana (Simple Random Sampling) kepada wajib pajak. Dikatakan simple (sederhana) karena pengambilan anggota sampel dari populasi dilakukan secara acak tanpa memperhatikan strata yang ada dalam populasi itu Jumlah sampel dalam penelitian ini menggunakan 100 responden yang diambil secara proporsional dari setiap desa. Total keseluruhan desa di kecamatan Ngimbang ada 19 desa, namun hanya diambi 5 desa dari keseluruha yang akan diberikan kuesioner dikarenakan keterbatasan waktu dan biaya.

\subsection{Metode Analisis Data}

Menurut Sugiyono (2014: 199) analisis data merupakan kegiatan setelah data dari seluruh responden terkumpul. Kegiatan dalam analisis data adalah mengelompokkan data berdasarkan variabel dan jenis responden, menstabulasi data berdasarkan variabel dari seluruh responden, menyajikan data dari setiap variabel, yang diteliti, melakukan perhitungan untuk menjawab rumusan masalah dan melakukan perhitungan untuk menguji hipotesis yang telah diajukan.

\section{Uji Kualitas Data}

Uji ini digunakan untuk mengetahui apakah instrument yang digunakan Valid dan Reliabel,

a. Uji Validitas

b. Uji Realibilitas

2. Metode Asumsi Klasik

Uji Asumsi Klasik adalah persyaratan statistika yang harus dipenuhi pada analisis Regresi Linier Berganda berbasis Ordinary Least Square (OLS).
a. Uji Multikolinieritas
b. Uji Heteroskedastisitas
c. Uji Normalitas 
3. Uji Model

Uji model digunakan untuk mengetahui pengaruh variabel bebas yaitu variabel Kesadaran wajib pajak dan sanksi pajak terhadap kepatuhan wajib pajak, dengan menggunakan Regresi Linear Berganda.

\section{Uji Hipotesis}

Dalam uji hipotesis ini digunakan untuk memastikan apakah variabel independen $(\mathrm{X})$ berpengaruh terhadap variabel dependen (Y). Uji hipotesis dilakukan dengan dua cara yaitu cara individu (parsial) dan bersama-sama (simultan)
a. Uji Parsial (Uji t)
b. Uji Simultan (Uji F)

\section{HASIL PENELITIAN DAN PEMBAHASAN}

\section{1) Uji Validitas}

Tabel 1. Hasil Uji Validitas

\begin{tabular}{|c|c|c|c|c|}
\hline $\begin{array}{c}\text { Varia } \\
\text { bel }\end{array}$ & $\begin{array}{c}\text { Indika } \\
\text { tor }\end{array}$ & r-htng & r-tabel & Indikator \\
\hline \multicolumn{5}{|c|}{ Variabel Kesadaran Wajib Pajak (X1) } \\
\hline \multirow{3}{*}{$\mathrm{X}_{1}$} & $\mathrm{X}_{1-1}$ & 0,842 & 0,1966 & Valid \\
\hline & $\mathrm{X}_{1-2}$ & 0,751 & 0,1966 & Valid \\
\hline & $\mathrm{X}_{1-3}$ & 0,851 & 0,1966 & Valid \\
\hline \multicolumn{5}{|c|}{ Variabel Sanksi Pajak (X2) } \\
\hline \multirow{3}{*}{$\mathrm{X}_{2}$} & $\mathrm{X}_{2-1}$ & 0,868 & 0,1966 & Valid \\
\hline & $\mathrm{X}_{2-2}$ & 0,813 & 0,1966 & Valid \\
\hline & $\mathrm{X}_{2-3}$ & 0,870 & 0,1966 & Valid \\
\hline \multicolumn{5}{|c|}{ Variabel Kepatuhan Wajib Pajak (Y) } \\
\hline \multirow{3}{*}{ Y } & $\mathrm{Y}_{1}$ & 0,827 & 0,1966 & Valid \\
\hline & $\mathrm{Y}_{2}$ & 0,818 & 0,1966 & Valid \\
\hline & $\mathrm{Y}_{3}$ & 0,841 & 0,1966 & Valid \\
\hline
\end{tabular}


Nilai r-tabel diperoleh dari $\mathrm{df}=\mathrm{n}-2$, n adalah jumlah sampel penelitian, perhitungan r-tabel $\mathrm{df}=100-2$ adalah untuk variabel kesadaran wajib pajak $\left(\mathrm{X}_{1}\right)$, r-tabel $\mathrm{df}=100-2$ adalah sanksi pajak $\left(\mathrm{X}_{2}\right)$. Dan selanjutnya nilai $\mathrm{r}$-tabel dilihat dari r-tabel produk moment dengan uji dua sisi $(\alpha=0.05)$. Jika nilai r-hitung lebih besar dari nilai r-tabel ( $\mathrm{r}$ hit > $\mathrm{r}$ tabel), maka indikator variabel kesadaran kesadaran wajib pajak $\left(\mathrm{X}_{1}\right)$, sanksi pajak $\left(\mathrm{X}_{2}\right)$ dinyatakan valid berdasarkan Uji Validitas untuk kedua variabel kesadaran wajib pajak dan sanksi pajak, diperoleh dari r-hitung > rtabel. Dengan demikian keseluruhan dari kedua variabel tersebut dinyatakan valid.

\section{2) Uji Reliabilitas}

Tabel 2. Hasil Uji Reliabilitas

\begin{tabular}{|c|c|c|c|}
\hline Indikator & $\begin{array}{c}\text { Cronbach } \\
\text { Alpha }\end{array}$ & $\begin{array}{c}\text { Standart } \\
\text { Reliable }\end{array}$ & $\begin{array}{c}\text { Karakteris } \\
\text { tik }\end{array}$ \\
\hline $\mathrm{X}_{1}$ & 0,794 & 0,6 & Reliable \\
\hline $\mathrm{X}_{2}$ & 0,809 & 0,6 & Reliable \\
\hline $\mathrm{Y}$ & 0,770 & 0,6 & Reliable \\
\hline
\end{tabular}

Sumber: Output SPSS 16 yang di olah, 2017

Berdasarkan hasil pengujian diatas dapat disimpulkan bahwa variabel $\left(\mathrm{X}_{1}\right)$ memiliki cronbach alpha sebesar 0,794 dikatakan reliabel karena memiliki nilai cronbach alpha> 0,06, variabel $\left(\mathrm{X}_{2}\right)$ sebesar 0,809>0,6 dan variabel $(\mathrm{Y})$ sebesar $0,770>0,6$. Sehingga seluruh variabel yang ada pada item penelitian ini dikatakan layak untuk pengujian selanjutnya.

\section{3) Uji Multikolinearitas}

Tabel 3. Uji Multikolinearitas

\begin{tabular}{|l|r|r|}
\hline \multirow{2}{*}{ Model } & \multicolumn{2}{|c|}{ Collinearity Statistics } \\
\cline { 2 - 3 } (Constant) & Tolerance & \multicolumn{1}{c|}{ VIF } \\
\hline x1 & 0.331 & 3.019 \\
x2 & 0.331 & 3.019 \\
\hline
\end{tabular}

Sumber: Output SPSS 16 yang di olah, 2017

Tabel di atas dapat menunjukan bahwa nilai Tolerance dari kedua variabel independen di atas 0.10 dan nilai VIP nya $3,019<10$. Dengan demikian dapat disimpulkan bahwa dalam model regresi tersebut tidak ada masalah multikolinearitas, maka model regresi ini layak untuk dipakai.

\section{4) Uji Heteroskedastisitas}

Tabel 4. Hasil Uji Glesjer

\begin{tabular}{|c|c|c|c|c|c|}
\hline \multirow[b]{2}{*}{ Model } & \multicolumn{2}{|c|}{$\begin{array}{l}\text { Unstandardized } \\
\text { Coefficients }\end{array}$} & \multirow{2}{*}{\begin{tabular}{|c|}
$\begin{array}{c}\text { Standardiz } \\
\text { ed } \\
\text { Coefficient } \\
\text { s }\end{array}$ \\
Beta \\
\end{tabular}} & \multirow[b]{2}{*}{$\mathrm{T}$} & \multirow[b]{2}{*}{ Sig. } \\
\hline & B & Std. Error & & & \\
\hline $\begin{array}{l}\text { (Const } \\
\text { ant) }\end{array}$ & -0.530 & 0.590 & & -0.899 & 0.371 \\
\hline $\mathrm{x} 1$ & 0.005 & 0.075 & 0.011 & 0.062 & 0.951 \\
\hline $\mathrm{x} 2$ & 0.088 & 0.076 & 0.200 & 1.159 & 0.250 \\
\hline
\end{tabular}

Jurnal Penelitian Ekonomi dan Akuntansi 
Berdasarkan tersebut, dapat diketahui bahwa masing-masing perhitungan variable menunjukan bahwa level sig > 0.05 yaitu $0.951>0.05$ untuk $\left(\mathrm{X}_{1}\right)$ dan $0.250>0.05\left(\mathrm{X}_{2}\right)$. Jadi dapat disimpulkan bahwa uji regresi ini tidak terjadi maslah Heteroskedastisitas.
5) Uji Normalitas

Tabel 5. Hasil Uji Normalitas

\begin{tabular}{|ll|r|}
\hline & & $\begin{array}{c}\text { Unstandardized } \\
\text { Residual }\end{array}$ \\
\hline $\mathrm{N}$ & Mean & 100 \\
Normal & Std. & 0.0000000 \\
Parameters & Deviation & 0.123 \\
& Absolute & 0.099 \\
Most & Positive & -0.123 \\
Extreme & Negative & 1.228 \\
Differences & 0.098 \\
Kolmogorov-Smirnov Z & 2-tailed) & Asymp. Sig. (207563 \\
\hline
\end{tabular}

Sumber: Output SPSS 16 yang di olah, 2017

Pada tabel diatas menunjukan bahwa sig lebih besar dari 0,05 . nilai Asymp. Sig. (2-tailed) $=0,98>0,05$. Sehingga tidak ditolak, yang berarti data residual berdistribusi normal.

\section{6) Uji Regresi Linear Berganda}

Tabel 6. Uji Regresi Linear Berganda

\begin{tabular}{|c|c|c|c|c|c|}
\hline \multirow[b]{2}{*}{ Model } & \multicolumn{2}{|c|}{$\begin{array}{c}\text { Unstandardized } \\
\text { Coefficients }\end{array}$} & \multirow{2}{*}{$\begin{array}{c}\text { Standardized } \\
\text { Coefficients } \\
\text { Beta }\end{array}$} & \multirow[b]{2}{*}{$\mathrm{T}$} & \multirow[b]{2}{*}{ Sig. } \\
\hline & B & Std. Error & & & \\
\hline (Constant) & 1.271 & 0.904 & & 1.406 & 0.163 \\
\hline $\mathrm{x} 1$ & 0.381 & 0.115 & 0.361 & 3.328 & 0.001 \\
\hline $\mathrm{x} 2$ & 0.501 & 0.117 & 0.465 & 4.284 & 0.000 \\
\hline
\end{tabular}

$$
\begin{gathered}
Y=a+b_{1} x_{1}+b_{2} X_{2} \\
Y=1,271+0,381 x_{1}+0,501 x_{2}
\end{gathered}
$$

Pada persamaan diatas tersebut menunjukan koefisien Linear. Masingmasing sebagai berikut : $\mathrm{a}=1,271$ merupakan nilai konstanta yang berarti apabila variabel bebas dalam penelitian $\left(\mathrm{X}_{1}\right.$ dan $\left.\mathrm{X}_{2}\right)$ yang mempengaruhi $=0$, maka 
hasil yang diperoleh dari (Y)

adalah sebesar 1,271.

$\mathrm{b}_{1}=0,381$ untuk variabel

$\mathrm{X}_{1}$ koefesien regresi $\left(\mathrm{b}_{1}\right)$

menunjukan nilai 0,381 yang

berarti apabila variabel $\mathrm{X}_{1}$

mengalami kenaikan satu

unit, maka Y akan

mengalami kenaikan sebesar

0,381 pada saat variabel

bebas yang lain sama dengan

nol (a dan $\left.\mathrm{X}_{1}=0\right)$.

$\mathrm{b}_{2}=0,501$ untuk variabel $\mathrm{X}_{2}$ koefesien regresi $\left(b_{2}\right)$ menunjukan nilai 0,501 apabila variabel

$\mathrm{X}_{2}$ mengalami kenaikan satu unit, maka Y akan mengalami kenaikan sebesar 0,501 pada saat variabel bebas yang lain sama dengan $\operatorname{nol}\left(\operatorname{a~dan~} \mathrm{X}_{1}=0\right)$.

Jadi dapat disimpulkan bahwa variabel $\mathrm{X}_{2}$ lebih dominan terhadap $\mathrm{Y}$
7) Uji Parsial (Uji t)

Tabel 7. Hasil Uji Parsial (Uji t)

\begin{tabular}{|c|c|c|c|c|c|}
\hline \multirow[b]{2}{*}{ Model } & \multicolumn{2}{|c|}{$\begin{array}{l}\text { Unstandardized } \\
\text { Coefficients }\end{array}$} & \multirow{2}{*}{\begin{tabular}{|c|}
$\begin{array}{c}\text { Standardiz } \\
\text { ed } \\
\text { Coefficient } \\
\text { s }\end{array}$ \\
Beta \\
\end{tabular}} & \multirow[b]{2}{*}{$\mathrm{T}$} & \multirow[b]{2}{*}{ Sig. } \\
\hline & B & Std. Error & & & \\
\hline $\begin{array}{l}\text { (Const } \\
\text { ant) }\end{array}$ & 1.271 & 0.904 & & 1.406 & 0.163 \\
\hline $\mathrm{x} 1$ & 0.381 & 0.115 & 0.361 & 3.328 & 0.001 \\
\hline $\mathrm{x} 2$ & 0.501 & 0.117 & 0.465 & 4.284 & 0.000 \\
\hline
\end{tabular}

Dengan analisis sebagai berikut:

1. Kesadaran Wajib Pajak

Dari hasil uji $\mathrm{t}$ diperoleh nilai $\mathrm{t}$ hitung (3.328) lebih besar dari pada t tabel (1.984). ( $\mathrm{df}=\mathrm{n}-\mathrm{k}, \alpha=0,05)$ sehingga $t_{\text {hitung }}>t_{\text {tabel }}$ maka $\mathrm{H}_{0}$ ditolak yang berarti ada pengaruh yang signifikan antara variabel $\mathrm{X}_{1}$ dan variabel Y.

\section{Sanksi Pajak}

Dari hasil uji $\mathrm{t}$ diperoleh nilai $\mathrm{t}$ hitung $(4,284)$ lebih besar dari pada $t$ tabel $(1,984) . \quad(\mathrm{df}=\mathrm{n}-\mathrm{k}, \alpha=0,05)$ sehingga $t_{\text {hitung }}>t_{\text {tabel }}$ maka $\mathrm{H}_{0}$ ditolak yang berarti ada pengaruh yang signifikan antara variabel $\mathrm{X}_{2}$ dan variabel Y. 


\section{8) Uji Simultan (Uji F)}

Tabel 8. Hasil Uji Simultan (Uji F)

\begin{tabular}{|l|r|r|r|r|r|}
\hline \multicolumn{1}{|c|}{ Model } & $\begin{array}{c}\text { Sum of } \\
\text { Squares }\end{array}$ & Df & $\begin{array}{c}\text { Mean } \\
\text { Square }\end{array}$ & F & Sig. \\
\hline Regression & 131.474 & 2 & 65.737 & 79.620 & 0.000 \\
& 80.086 & 97 & 0.826 & & \\
Residual & & & & \\
Total & 211.560 & 99 & & & \\
\hline
\end{tabular}

Sumber: Output SPSS 16 yang di olah, 2017

Dari tabel diatas diperoleh $\mathrm{F}_{\text {hitung }}$ sebesar 79.620 sedangkan $\mathrm{F}_{\text {tabel }}$ sebesar 2,70. ( df1 = k-1, df2 = n-k, $\alpha=0,05)$. Karena $F_{\text {hitung }}>F_{\text {tabel }}$ maka Ho ditolak artinya bahwa variabel bebas $\left(\mathrm{X}_{1}\right.$ dan $\left.\mathrm{X}_{2}\right)$ secara bersama-sama mempunyai pengaruh yang signifikan terhadap Y.

\section{PENUTUP}

Berdasarkan penelitian yang telah dilakukan dan pembahasan mengenai Pengaruh Kesadaran Wajib Pajak dan Sanksi Pajak Terhadap Kepatuhan Wajib Pajak dalam Membayar PBB di Kecamatan Ngimbang Kabupaten Lamongan Tahun 2016, maka dapat diambil kesimpulan sebagai berikut:

1. Dari hasil uji t (uji parsial) diperoleh nilai $\mathrm{t}$ hitung kepatuhan wajib pajak (3.328) lebih besar dari pada t tabel (1.984), dan $\mathrm{t}$ hitung sanksi pajak diperoleh nilai t hitung (4.284) lebih besar dari pada $\mathrm{t}$ tabel (1.984) sehingga dapat diasumsikan bahwa kedua variabel bebas mempunyai pengaruh yang signifikan terhadap Kepatuhan Wajib Pajak dalam Membayar PBB di Kecamatan Ngimbang Kabupaten Lamongan Tahun 2016.

2. Dari hasil uji F (uji simultan) diperoleh $\mathrm{F}_{\text {hitung }}$ sebesar 79.620 sedangkan $F_{\text {tabel }}$ sebesar 2,70 . Karena $\mathrm{F}_{\text {hitung }}>\mathrm{F}_{\text {tabel }}$ maka Ho ditolak artinya bahwa variabel bebas (kepatuhan wajib pajak dan sanksi pajak) secara bersamasama mempunyai pengaruh yang signifikan terhadap Kepatuhan Wajib Pajak dalam Membayar PBB di Kecamatan Ngimbang Kabupaten Lamongan Tahun 2016.

3. Dari persamaan regresi berganda

$$
\begin{aligned}
& \mathrm{Y}=1,271+0,381 \mathrm{X} 1+0,501 \\
& \mathrm{X} 2+\mathrm{e}
\end{aligned}
$$

Variabel bebas yang paling dominan mempengaruhi kepatuhan wajib pajak dalam membayar PBB adalah variabel sanksi pajak. Dikarenakan standar koefesien beta sebesar 0,465 yang lebih besar dari variabel kesadaran wajib pajak. 


\section{DAFTAR PUSTAKA}

Caprian, Iulia. 2015. Peran Sanksi Pajak Dalam Wajib Pajak Pendidikan Penulis. Jurnal Modolva: PhD, Associate Professor, Moldova State University

Mardiasmo. 2011. Perpajakan. Edisi Revisi. Andi. Yogyakarta

Martha, Despina. 2013. Keterangan Mengenai Kegiatan Wajib Pajak Didekralasikan Aktif dan Konsekuensi Ekonomis. Jurnal Rumania: Alexandru Ioan Cuza University

Pankiewicz, Pawel. 2011. Individu Wajib Pajak Utilitas Fungsi dengan Optimization Pajak dan Penipuan Lingkungan. Jurnal Polandia: Wyższa Szkoła Informatyki i Zarządzania

Sudirman, Rismawati dan Ammirudin antong. 2016. Perpajakan, Pendekatan, Teori dan Praktek. Empatdua Media, Makassar

Sugiyono. 2014. Metode Penelitian Kualitatif Kuantitatif dan $R \& D$. Bandung: Alfabeta.

Supramono. 2014. Perpajakan Indonesia. Edisi Revisi. Andi. yogyakarta 